Technical Papers

\title{
$\mathrm{HEV}$ 계전기의 소음분산 저감에 관한 실험적 연구 \\ 김원진*
}

(Manuscript received: Dec, 10, 2012 / Revised: Mar, 1, 2013 / Accepted: Mar, 8, 2013)

\section{Experimental Study on the Reduction of Noise Dispersion for HEV Relay}

\author{
Wonjin Kim*
}

\begin{abstract}
The dispersion of acoustic noise during the turn-on and turn-off switching of HEV(hybrid electric vehicle) relay was experimentally analyzed to identify the reason for the dispersion of noise level. An effective method was proposed to reduce the dispersion of noise level. First, a method to wrap the side of moving core with a tape was adopted to reduce the transverse vibration. It enabled the moving core to make a consistent motion and reduce the dispersion of noise level from switching operation of relay. Second, the dispersion of noise level from vibration transmission of parts such as the outer frame and yoke caulking part of relay were tested to find out main sources. From this result, it was identified that the yoke caulking part made inconsistent transient vibration and noise dispersion.
\end{abstract}

Key Words : Relay(계전기), Noise dispersion(소음산포), Standard deviation(표준편차)

\section{1. 서 론}

최근 세계적으로 환경과 화석연료 문제가 대두되면서 친환경 자동차인 그린카에 대한 관심이 급증하고 있다. 그린카란 전기 자동차, 플러그인 하이브리드 자동차, 연료전지자동차 등 화석 연료를 대체하여 환경오염을 크게 줄일 수 있는 자동차로, 국내 외에서 그린카의 핵심 전장 부품에 관한 개발 연구가 활발히 진행되고 있다 ${ }^{(1)}$.

그린카의 핵심 전장부품 중의 하나인 계전기(relay)는 배터 리와 $\mathrm{PCU}$ (power control unit) 사이에 장착되어 자동차의 동 력을 개폐하는 일종의 스위치 역할을 하는 장치이다 ${ }^{(2)}$. 계전기 는 주로 배터리 전력을 안정적으로 공급 및 차단하여 커패시터, 모터 또는 하니스(harness)의 단시간 단락 전류 차단 실패를 예
방하며, 급정지 시에 발생하는 역방향 재생 전류로부터 전장 부품을 보호하는 기능을 한다 ${ }^{(3)}$.

계전기를 대상으로 진행된 연구사례 중에는 먼저 계전기의 접점 간의 충격 소음 및 바운스 특성을 향상시킬 수 있는 최적 화 설계 기법을 제안한 충격 및 바운스 특성 향상을 위한 하이 브리드 자동차용 계전기(HEV-Relay)의 설계에 관한 연구 ${ }^{(4)}$ 가 있다. 또한 고전압 직류 계전기의 폐로 동작 시에 발생하는 소 음 저감을 위하여 이중 접압스프링 구조를 제안한 고전압 직류 계전기의 소음 저감에 관한 연구 ${ }^{(5)}$ 가 있고, 계전기 단품의 밀폐 와 배터리 팩으로 전달되는 진동을 절연하는 방법을 제안한 하 이브리드 자동차용 계전기 모듈의 소음저감에 관한 실험적 연 $ㄱ ㅜ(6)^{(6)}$ 있다.

계전기는 개폐과정 중에 소음이 발생된다. 이 소음은 하나의 
계전기가 반복적으로 작동될 때에 폐로와 개로 과정에서 각각 산포가 발생되고, 계전기 간에서도 개폐과정 중에 각각 산포가 발생된다. 이러한 소음산포는 계전기의 불량을 발생시키고, 품 질관리에 어려움을 준다. 따라서 본 연구에서는 하이브리드 자 동차용 계전기에서 발생되는 소음저감을 위한 연구와는 별도 로 소음산포에 대한 원인과 부품을 규명하고, 소음산포를 저감 할 수 있는 방안을 제시하고자 한다.

\section{2. 계전기의 소음 발생 메커니즘}

계전기는 주전류의 단속을 위하여 폐로(turn on)와 개로(turn off) 작동을 반복하며, 각각의 동작기구는 Fig. 1의 (a)와 (b)에 서와 같다. 먼저 폐로과정은 내부의 코일에 전류가 흐르면서 시작된다. 이 코일의 전류로 인한 유도자기장에 의해 코어부분 은 자성을 가지게 된다.

이때 고정코어(fixed core)와 이동코어(moving core) 사이에 는 인력이 작용하게 되는데, 이 힘으로 샤프트와 이동코어가

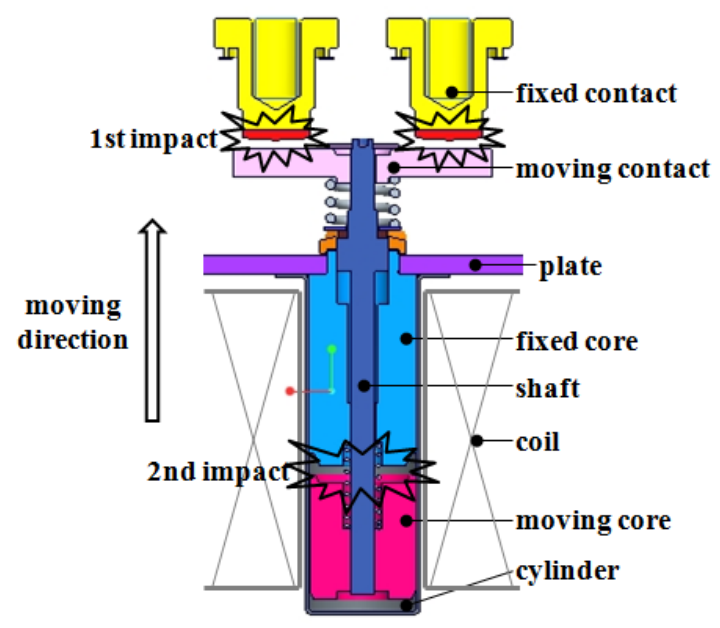

(a) On

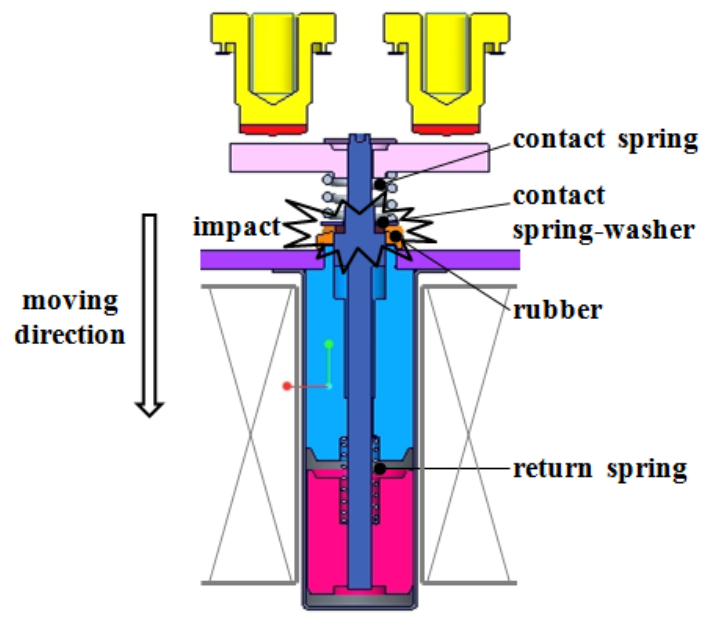

(b) Off

Fig. 1 Operation mechanism of relay
상 방향으로 운동하면서 상부의 고정단자(fixed contact) 사이 를 통전시키게 된다. 고정단자와 이동단자(moving contact)가 서로 부딪히고 난 후에도 이동코어는 고정코어와 부딪힐 때까 지 상 방향으로 운동하게 된다. 이때 계전기 내부에서는 단자 사이의 충돌에 의한 충격력과 코어 사이의 충돌에 의한 충격력 이 연속해서 발생하여 소음을 유발시킨다. 계전기의 개로과정 에서는 코일에 전류가 단락되어 고정과 이동 코어 사이의 작용 인력이 소멸되면서 복원 스프링과 접촉스프링(contact spring) 에 의해 샤프트는 원래 위치로 복귀하게 되고, 이때 접압 스프 링 와셔가 고무와 충돌하면서 충격력이 발생되어 소음을 유발 시킨다. 이러한 소음방사 과정은 크게 개폐과정에서 발생되는 충돌에 의한 충격음과 충격력이 계전기의 부품으로 전달되어 발생되는 구조진동음으로 나눌 수 있다 ${ }^{(7)}$. 결과적으로 계전기 에서 발생되는 소음산포는 충격과정에서의 충돌 부품과 충격 력의 전달에 의하여 가진되는 부품에 의해 결정된다고 할 수 있다. 따라서 효과적으로 소음산포를 유발하는 부품을 규명하 기 위하여 충격입력과 충격전달 부분으로 구분하여 분석하였다.

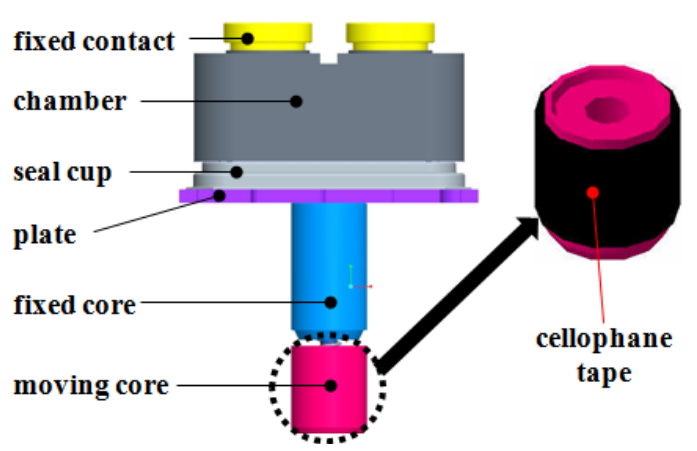

Fig. 2 Moving core wrapped with cellophane tape

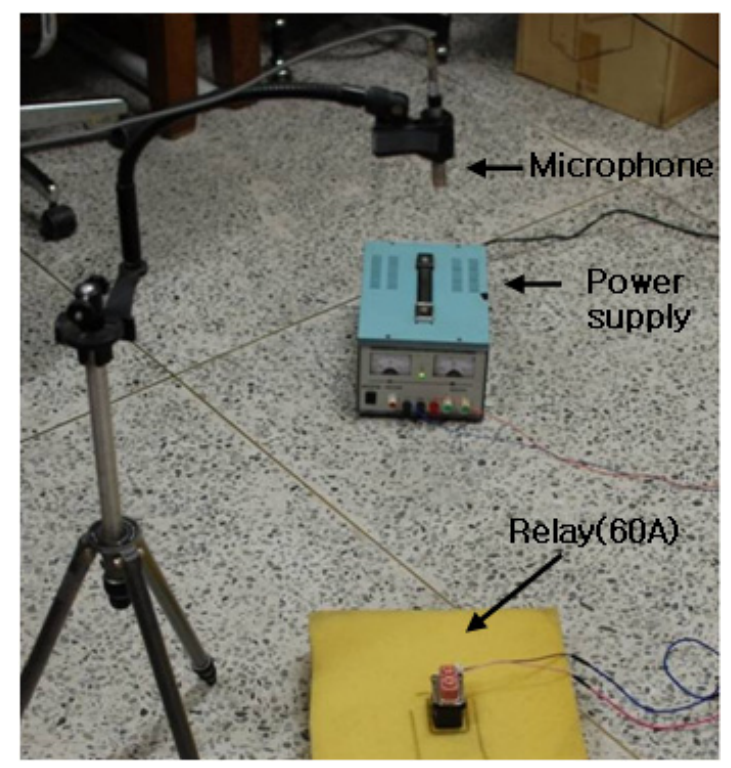

Fig. 3 Experimental setup 
Table 1 Noise dispersion levels of relay having a moving core with tape

\begin{tabular}{|c|c|c|c|c|c|}
\hline & & Sample & $\begin{array}{l}\text { Avg. } \\
\text { Overall }\end{array}$ & $\begin{array}{l}\text { Standard } \\
\text { deviation }\end{array}$ & Difference \\
\hline & 1 & existing & 59.2 & 0.87 & 3.2 \\
\hline & 1 & with tape & 59.3 & 0.47 & 2.0 \\
\hline $\mathrm{On}$ & 2 & existing & 59.6 & 0.92 & 3.2 \\
\hline UII & 2 & with tape & 59.9 & 0.51 & 2.0 \\
\hline & 3 & existing & 58.4 & 0.58 & 2.4 \\
\hline & $J$ & with tape & 58.7 & 0.26 & 1.0 \\
\hline & 1 & existing & 50.8 & 1.13 & 4.0 \\
\hline & 1 & with tape & 47.7 & 0.59 & 1.8 \\
\hline Aff & 2 & existing & 49.7 & 0.74 & 2.7 \\
\hline UI & 2 & with tape & 47.1 & 0.52 & 1.7 \\
\hline & 3 & existing & 47.4 & 1.04 & 4.2 \\
\hline & $J$ & with tape & 45.3 & 0.49 & 1.5 \\
\hline
\end{tabular}

\section{3. 충격입력 과정의 소음산포 분석}

계전기의 개폐과정은 자성의 유무에 의한 이동코어의 이동방 향에 따라 결정된다. 이동코어는 실린더 내부에 위치하여 상하 운동을 하며 이동코어의 옆면과 실린더의 벽면 사이에는 간극 이 존재한다. 이 간극 때문에 이동코어가 운동할 때에 이동코어 의 수평방향 진동이 발생하고, 이로 인하여 계전기의 개폐과정 에서 불균일한 충돌로 소음산포가 유발될 가능성이 있다. 따라 서 이동코어의 옆면과 실린더 벽면 사이의 간극에서 발생되는 이동코어의 수평방향 진동이 소음산포에 주는 영향을 분석하 였다. 이동코어의 옆면과 실린더 벽면 사이의 간극에서 발생되 는 진동을 저감시켜 계전기의 개폐과정이 반복될 때마다 충돌 이 일관성 있게 발생될 수 있도록 이동코어의 옆면에 Fig. 2와 같이 한 겹의 셀로판 테이프를 부착하여 실린더 벽면과의 간극 을 축소하였다. 실험방법은 Fig. 3과 같이 계전기(60A)의 시험 규격에 따라 전원공급기로 개폐를 작동시키면서 상단 $60 \mathrm{~cm}$ 위치에 마이크로폰으로 음압을 측정하였다. 동일한 3 개의 계전 기 샘플을 대상으로 각각 20 회씩 측정하여 음압레벨의 평균을 구하였고, 표준편차와 20 회 측정한 음압레벨 중에서 최대·최 소 음압레벨의 차(difference) 등 산포도(dispersion)를 구하여 폐로와 개로 과정에서 각각의 소음산포를 분석하고, 결과는 Table 1과 Fig. 4에 정리하였다.

분석 결과에서 셀로판 테이프를 부착한 경우에 개로과정에서 는 테이프의 감쇠 효과에 의해 소음레벨이 저감되지만 폐로과 정에서는 큰 변화가 없는 것은 개로과정에서는 이동코어의 직 접적인 충돌에 의해 소음이 발생되지만 폐로과정에서 소음은

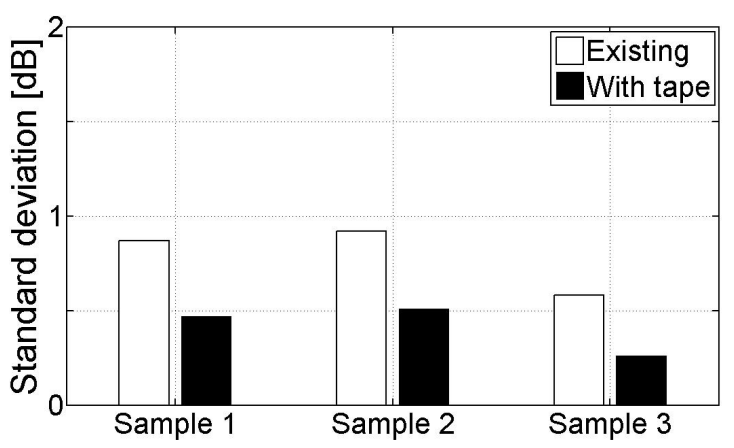

(a) On

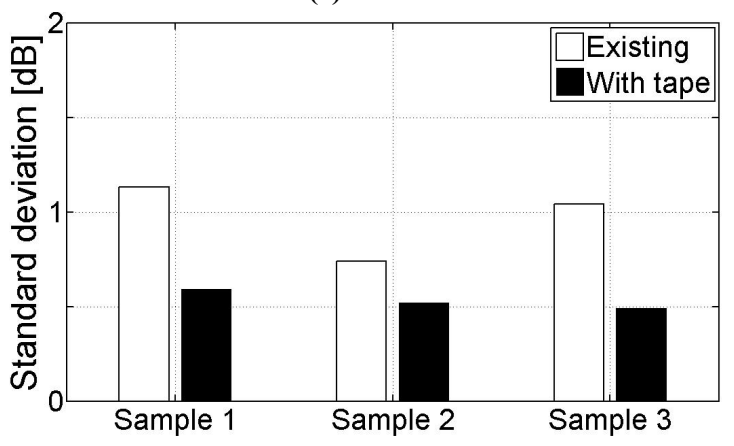

(b) Off

Fig. 4 Noise standard deviations of relay having a moving core with tape

이동코어와 별도 부품인 이동단자의 충돌에 의해서 1 차적으로 소음이 발생되기 때문이다. 그러나 모든 샘플들은 폐로와 개로 과정에서 표준편차와 최대·최소 음압레벨의 차가 모두 감소된 것을 알 수 있다. 따라서 이동코어의 옆면과 실린더 벽면 사이 의 간극에서 발생되는 이동코어의 진동은 계전기의 개폐과정 에서 발생되는 충돌을 불균일하게 유발하고 충격 과정에서 소 음의 산포 발생에 영향을 주는 것으로 판단된다. 셀로판 테이프 는 단지 산포의 원인을 분석하기 위한 것이고, 실제 적용상에 있어서는 이동코어의 지름 또는 실린더 내부지름 등의 수정을 통한 간극 조정이 필요하다.

\section{4. 충격전달 과정의 소음산포 분석}

\section{1 외곽 프레임의 소음산포 영향도}

외곽 프레임은 Fig. 5의 (a)와 같으며, (b)의 내부 부품, 어셈 블리(mechanism assembly)를 보호하는 역할을 하고, 상부 프 레임(upper frame), 하부 프레임(lower frame), 터미널 블록 (terminal block)으로 구성된다. 이러한 외곽 프레임은 계전기 의 개폐과정 중에서 발생되는 충격음으로 인하여 가진될 수 있 으므로 외곽 프레임의 소음산포에 대한 영향을 분석하였다. 4 개의 계전기 완제품을 대상으로 분석하였다. 외곽 프레임의 유 무에 따른 개폐과정에서 각각 소음산포를 분석하고, 결과는 Table 2와 Fig. 6에 정리하였다. 폐로과정에서는 외곽 프레임 


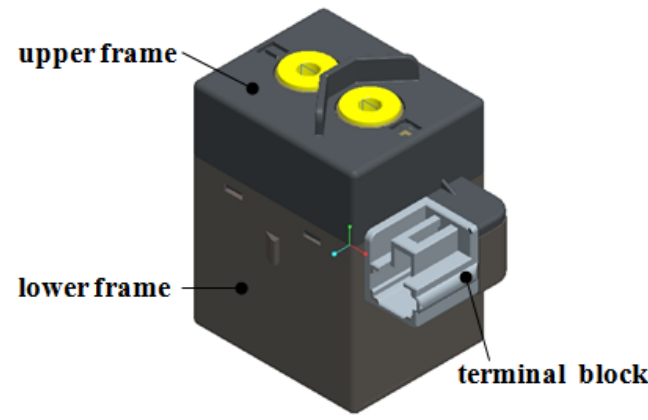

(a) Relay

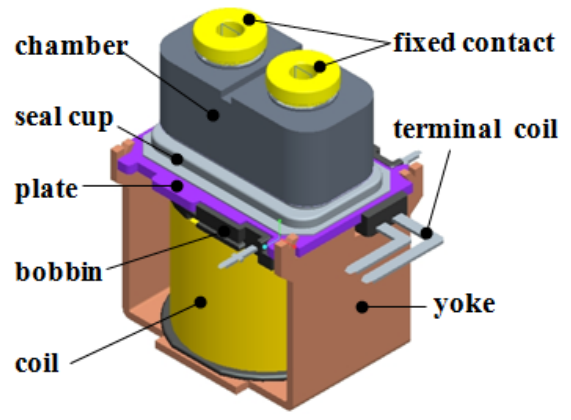

(b) Mechanism assembly

Fig. 5 Relay and mechanism assembly

Table 2 Noise dispersion levels of relay without outer frame

\begin{tabular}{|c|c|c|c|c|c|}
\hline & & Sample & $\begin{array}{c}\text { Avg. } \\
\text { Overall } \\
\text { level } \\
{[\mathrm{dBA}]}\end{array}$ & $\begin{array}{c}\text { Standard } \\
\text { deviation } \\
{[\mathrm{dB}]}\end{array}$ & $\begin{array}{c}\text { Difference } \\
{[\mathrm{dB}]}\end{array}$ \\
\hline \multirow{8}{*}{ On } & \multirow{2}{*}{1} & existing & 54.4 & 0.37 & 1.4 \\
\hline & & without & 59.8 & 0.65 & 2.0 \\
\hline & \multirow{2}{*}{2} & existing & 54.1 & 0.48 & 1.9 \\
\hline & & without & 61.8 & 0.74 & 2.5 \\
\hline & \multirow{2}{*}{3} & existing & 54.9 & 0.41 & 1.4 \\
\hline & & without & 59.9 & 0.45 & 1.4 \\
\hline & 4 & existing & 55.2 & 0.58 & 2.2 \\
\hline & & without & 60.4 & 0.77 & 2.8 \\
\hline \multirow{8}{*}{ Off } & \multirow{2}{*}{1} & existing & 45.4 & 0.71 & 2.7 \\
\hline & & without & 44.6 & 0.74 & 2.9 \\
\hline & \multirow{2}{*}{2} & existing & 43.1 & 0.85 & 4.0 \\
\hline & & without & 42.7 & 0.92 & 3.7 \\
\hline & \multirow{2}{*}{3} & existing & 45.5 & 0.68 & 2.6 \\
\hline & & without & 43.4 & 1.41 & 5.5 \\
\hline & \multirow{2}{*}{4} & existing & 43.8 & 0.75 & 2.5 \\
\hline & & without & 44.8 & 0.97 & 3.2 \\
\hline
\end{tabular}

이 없는 경우에 4개의 샘플들이 모두 음압레벨의 평균이 증가 되고, 표준편차와 최대·최소 음압레벨의 차도 전체적으로 증가 된 것을 알 수 있다. 개로과정에서는 모든 샘플들이 표준편차가

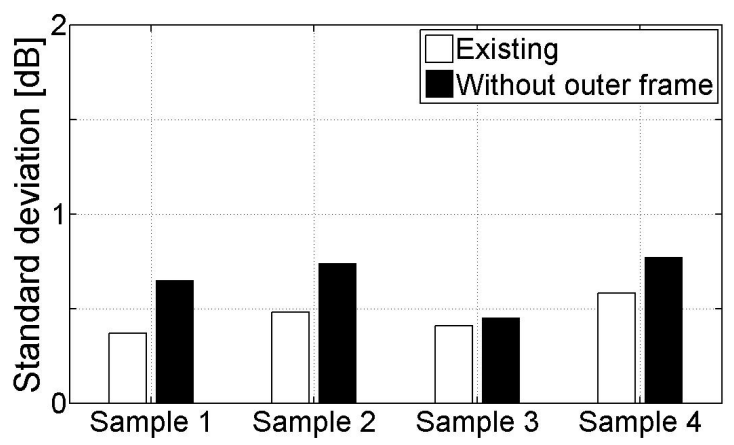

(a) On

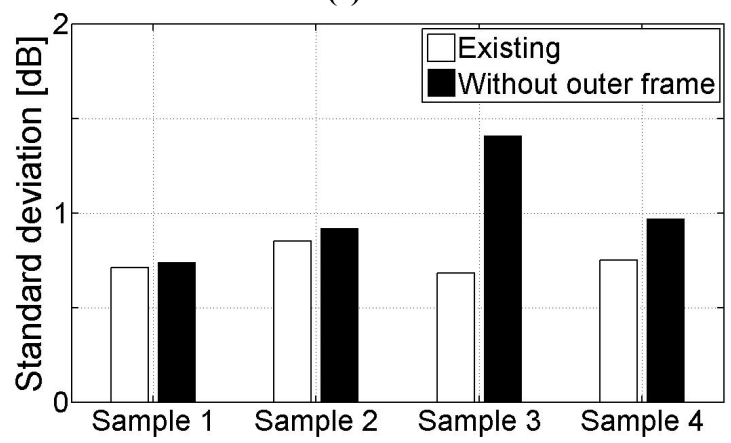

(b) Off

Fig. 6 Standard deviation levels of noise for relay without outer frame

증가되지만, 음압레벨의 평균과 최대·최소 음압레벨의 차는 경 향성이 없는 것을 알 수 있다. 따라서 외곽 프레임은 폐로과정 에서 소음산포를 저감하는 효과가 있으며, 개로과정에서는 소 음산포에 주는 영향이 작으므로 소음 전달 과정에서 소음산포 를 유발하는 부품이 아닌 것으로 판단된다.

\section{2 전달 부품의 소음산포 영향도}

충격전달 과정에서 외곽 프레임은 소음산포를 유발하는 부품 이 아니므로 여기서는 외곽 프레임을 제외한 메커니즘 어셈블 리를 구성하는 부품들이나 결합이 취약한 부분이 산포에 주는 영향을 분석하였다. 측정 대상은 4.1절에서 사용한 4개의 메커 니즘 어셈블리이다. 고무계통의 제진 댐핑재(damping material) 를 사용하여 소음산포를 발생할 가능성이 있는 부품에 부착하 는 방법으로 충격음의 전달을 절연하였다. 그리고 해당부품의 절연에 의한 효과를 평가하기 위하여 소음을 측정하고, 산포도 를 구하였다. 여기서 댐핑재는 소음산포를 저감하기 위한 실제 적용 대책은 아니고, 단지 산포를 발생시키는 부품을 규명하기 위한 것이다. 댐핑재는 다음과 같이 3 가지 부품에 각각 부착하 였고, 분석 결과 중에서 소음산포에 영향이 없는 부품의 결과 데이터는 나타내지 않았다.

(1) 요크(yoke)에 Fig. 7 (a)와 같이 댐핑재를 부착하여 소음을 측정하였다. 모든 샘플들은 개폐과정 시에 표준편차와 최 


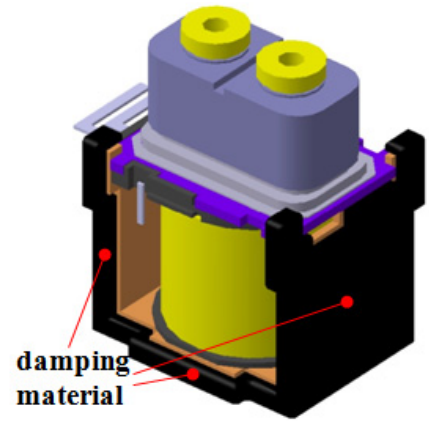

(a) Yoke

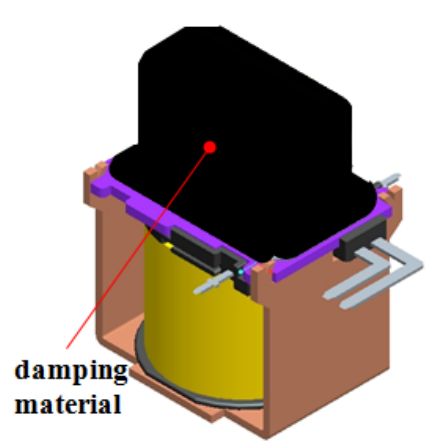

(b) Chamber assembly

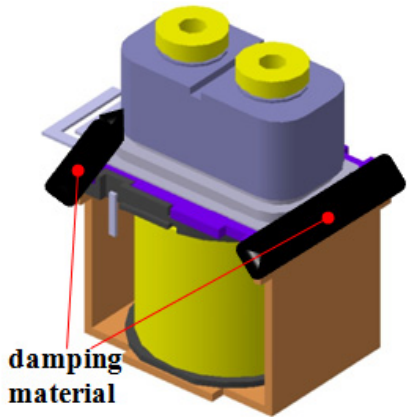

(c) Caulking area of yoke and plate

Fig. 7 Assembles with damping material

대·최소 음압레벨의 차에서 모두 경향성이 나타나지 않았 다. 따라서 요크는 소음의 산포에 주는 영향이 작은 것으로 판단된다.

(2) 챔버 어셈블리는 Fig. 5 (b)에서와 같이 고정단자와 챔버, 씰컵(seal cup)으로 구성된 부품이다. 이러한 챔버 어셈블 리에 Fig. 7 (b)와 같이 댐핑재를 부착하여 소음을 분석하였다. 따라서 챔버 어셈블리는 소음 전달 과정에서 소음산포에 주는 영향이 작은 것으로 판단된다.

(3) 메커니즘 어셈블리를 구성하는 부품 중에 요크와 플레이트 는 코킹으로 조립되며, 용접으로 조립되는 다른 부분들 보 다 상대적으로 취약할 것으로 판단된다. 그래서 Fig. 7 (c) 와 같이 요크와 플레이트의 체결 부분에 댐핑재를 부착하 여 충격력의 전달을 절연시킨 후에 소음산포를 분석하였 다. Table 3과 Fig. 8에 나타낸 결과에서 알 수 있듯이 댐핑 재를 부착했을 때에 모든 샘플들은 폐로와 개로 과정에서
Table 3 Noise dispersion levels of relay with damping material

\begin{tabular}{|c|c|c|c|c|c|}
\hline & & Sample & $\begin{array}{c}\text { Avg. } \\
\text { Overall } \\
\text { level } \\
{[\mathrm{dBA}]}\end{array}$ & $\begin{array}{c}\text { Standard } \\
\text { deviation } \\
{[\mathrm{dB}]}\end{array}$ & $\begin{array}{c}\text { Difference } \\
{[\mathrm{dB}]}\end{array}$ \\
\hline \multirow{8}{*}{ On } & \multirow{2}{*}{1} & existing & 59.8 & 0.65 & 2.0 \\
\hline & & damping & 55.4 & 0.37 & 1.3 \\
\hline & \multirow{2}{*}{2} & existing & 61.8 & 0.74 & 2.5 \\
\hline & & damping & 57.4 & 0.20 & 0.7 \\
\hline & \multirow{2}{*}{3} & existing & 59.9 & 0.45 & 1.4 \\
\hline & & damping & 55.9 & 0.24 & 0.9 \\
\hline & \multirow{2}{*}{4} & existing & 60.4 & 0.77 & 2.8 \\
\hline & & damping & 55.7 & 0.53 & 1.9 \\
\hline \multirow{8}{*}{ Off } & \multirow{2}{*}{1} & existing & 44.6 & 0.74 & 2.9 \\
\hline & & damping & 41.5 & 0.35 & 1.7 \\
\hline & \multirow{2}{*}{2} & existing & 42.7 & 0.92 & 3.7 \\
\hline & & damping & 38.9 & 0.65 & 2.2 \\
\hline & \multirow{2}{*}{3} & existing & 43.4 & 1.41 & 5.5 \\
\hline & & damping & 39.4 & 0.73 & 2.5 \\
\hline & \multirow{2}{*}{4} & existing & 44.8 & 0.97 & 3.2 \\
\hline & & damping & 40.0 & 0.59 & 2.2 \\
\hline
\end{tabular}

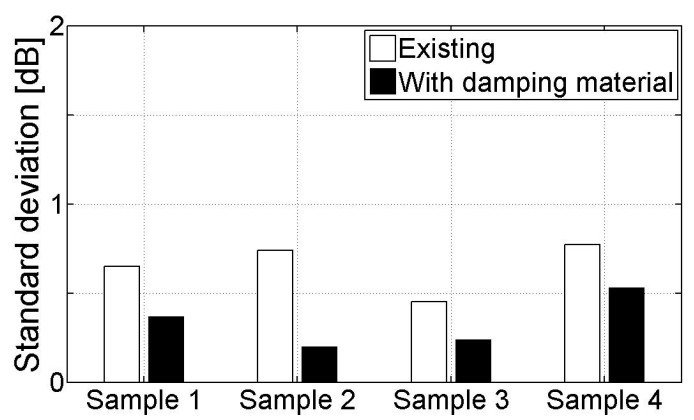

(a) On

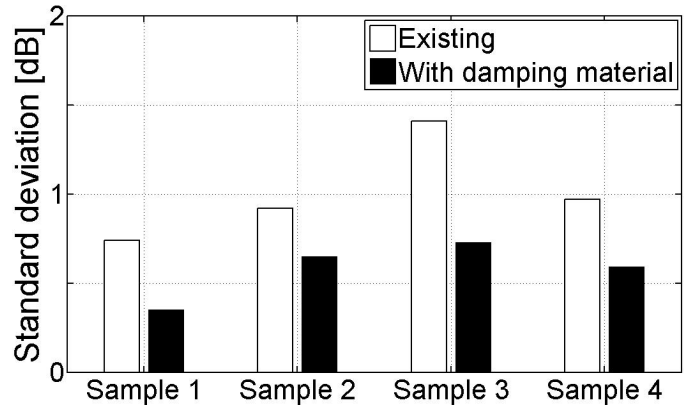

(b) Off

Fig. 8 Noise standard deviations of relay with damping material

표준편차와 최대·최소 음압레벨의 차가 모두 저감된다. 따 라서 요크와 플레이트의 체결 부분은 소음 전달 과정에서 충격 가진으로 인하여 소음산포에 영향을 주는 것으로 판 단된다. 
Table 4 Noise dispersion levels of relay having a moving core with tape and caulking area with damping material

\begin{tabular}{c|c|c|c|c}
\hline \hline \multirow{7}{*}{ Sample } & $\begin{array}{c}\text { Avg. } \\
\text { Overall } \\
\text { level } \\
{[\mathrm{dBA}]}\end{array}$ & $\begin{array}{c}\text { Standard } \\
\text { deviation } \\
{[\mathrm{dB}]}\end{array}$ & $\begin{array}{c}\text { Difference } \\
{[\mathrm{dB}]}\end{array}$ \\
\hline \multirow{4}{*}{ On } & 1 & 57.7 & 0.54 & 1.8 \\
\cline { 2 - 5 } & 2 & 57.4 & 0.53 & 1.8 \\
\cline { 2 - 5 } & 3 & 55.9 & 0.38 & 1.3 \\
\hline \multirow{3}{*}{ Off } & 1 & 41.1 & 0.48 & 1.6 \\
\cline { 2 - 5 } & 2 & 41.5 & 0.51 & 1.7 \\
\cline { 2 - 5 } & 3 & 40.7 & 0.32 & 1.3 \\
\hline
\end{tabular}

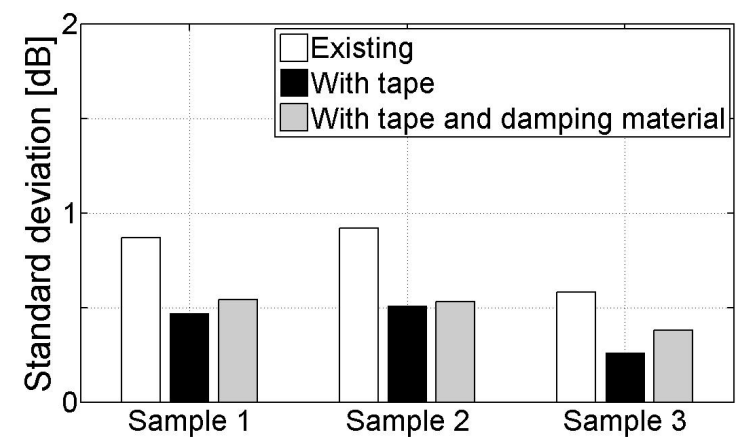

(a) On

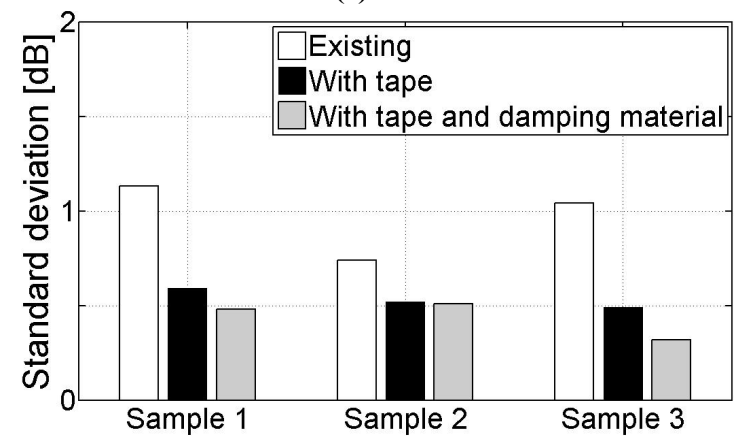

(b) Off

Fig. 9 Noise standard deviations of relay having a moving core with tape and caulking area with damping material

\section{5. 소음산포 저감방법 제안}

소음산포 저감방법을 제안하기 위하여 이동코어에 셀로판 테 이프와 요크와 플레이트의 체결 부분에 댐핑재를 함께 부착한 샘플의 소음산포를 분석하였다. 이동코어 부품을 수정하기 위 하여 3장에서 사용한 3 개의 샘플을 대상으로 분석하였다. 측정 결과는 Table 4와 같고, Fig. 9는 Table 1과 Table 4의 표준편 차를 비교하여 나타낸 것이다. 결과를 보면 두 방법을 함께 적 용했을 때에 모든 샘플들의 소음산포는 개폐과정에서 표준편 차와 최대·최소 음압레벨의 차가 전체적으로 저감됨을 알 수
있다. 이동코어에 테이프를 부착하여 수정한 샘플의 결과와 비 교해 보면 요크와 플레이트의 체결 부위에 댐핑재를 부착하지 않고도 소음산포를 충분히 저감함을 알 수 있다. 이것은 충격입 력에 해당되는 이동코어의 충격이 일관되기 때문에 충격력 전 달과정에서 소음 변동이 크게 발생하지 않는 것으로 판단된다. 따라서 소음산포를 저감하기 위해서는 1 차적으로 이동코어의 수평진동을 억제하기 위한 코어와 실린더 사이의 간극의 조정 또는 정밀한 가공이 필요하며, 2차적인 방법으로 요크와 플레 이트의 체결 부분을 용접 또는 일체형 제작으로 완전결합이 되 도록 체결구조를 수정하는 것이 필요하다.

\section{6. 결 론}

하이브리드 자동차용 계전기에서 발생되는 소음산포에 대한 원인과 부품을 규명하였으며, 결과를 정리하면 다음과 같다.

첫째 충격입력에 의한 소음산포 분석에 있어서는 이동코어와 실린더 사이의 간극을 최소화하여 이동코어의 수평방향 진동 을 억제하므로 충격부에서 일관된 충돌이 가능하도록 수정한 결과, 기존제품 대비하여 소음산포를 상당량 저감할 수 있었다.

둘째 충격전달에 의한 소음산포 분석에 있어서는 각 부분에 댐핑재를 부착하는 방법을 적용하여 주요 소음산포 발생 부품 을 규명하였다. 충격전달과정에서는 요크와 플레이트의 체결 부위에서의 소음산포가 주로 발생되는 것으로 확인되었다.

결론적으로 계전기의 소음산포를 저감하기 위해서는 이동코 어와 실린더 사이의 간극의 조정 또는 정밀한 가공이 우선적으 로 선행되어야 하고, 요크와 플레이트의 체결 부분을 완전결합 이 되도록 용접 또는 일체형 제작 등과 같은 구조로 수정하는 것이 필요하다.

\section{후 기}

본 연구는 2012년도 계명대학교 비사연구기금으로 이루어졌음.

\section{References}

(1) LS Industrial Systems, 2010, viewed 11 November 2012, <http://www.bisd.or.kr/seminarPage/pds_data/100603 s2_08.pdf $>$.

(2) Lee, S. H., Yoon, H. S., and Koh, C. S., 2010, "Design of Solenoid Actuator for EV-Relay," Proceedings of KIEE Electrical Machinery and Energy Conversion Systems So ciety Annual Autumn Conference, pp. 228 230.

(3) LS Industrial Systems, n.d., viewed 11 November 2012, $<\mathrm{http} / / /$ www.lsis.co.kr/ls/product/product_detail.asp?pro 
duct_code $=\mathrm{P} 00695>$.

(4) Ko, Y. K., Cho, S. S., Huh, H., Lee, S. Y., Park, H. T., and Oh, I. S., 2008, "Design of HEV-Relay to Improve Impact and Bounce Characteristics," Proceedings of KSME Annual Autumn Conference, pp. 491 496.

(5) Lee, G. H., Kim, Y. B., Park, H. T., and Son, J. W., 2007, "Study on the Noise Reduction of the High Voltage DC Relay," Proceedings of KSNVE Annual Autumn Conference, pp. 788 792.
(6) Seo, J. Y., and Kim, W. J., 2010, “An Experimental Study on the Noise Reduction Method of HEV-relay Module," Trans. of the Korean Soc. for Precision Engineering, Vol. 27, No. 10, pp. 77 83.

(7) Kim, K. H., and Kim, Y. H., 2008, "Modeling impact force and transfer function for reducing relay impact noise," Proceedings of KSNVE Annual Autumn Conference, pp. $646 \sim 649$. 